\title{
La dialéctica del querer y del poder en San Agustín
}

Tres son los conceptos que dinamizan fundamentalmente la especulación agustiniana: racionalidad, verdad y felicidad. $\mathrm{Y}$ a ellos corresponde formular (y darle contestación) esta pregunta esencial: “ ¿Existimatisne beatos nos esse posse, etiam non inventa veritate?" " ${ }^{1}$. ¿Crees que podremos ser felices aun sin llegar a encontrar la verdad?". Efectivamente el hombre busca la felicidad; ahora bien, esta no existe sin la rerdad que, a su vez, debe ser racional.

Podemos distinguir dos fases en el proceso dialéctico de la racionalidad, de la verdad y de la felicidad: una fase negativa y otra afirmativa. En la primera, se pueden distinguir, a su vez, dos momentos: el de la relación del espíritu con el mundo exterior y el de la propia división interna del espíritu mismo.

Aunque estas dos fases se hallen simultáneamente presentes, ya que son correlativas entre sí, es posible, sin embargo, describir separadamente cada una de ellas.

Al comenzar por la fase negativa, que en gran parte es como una preparación de movimiento dialéctico positivo, podemos seguir una trayectoria que va de la exterioridad a una interioridad cada vez mayor. Volvemos a encontrar aquí un diálogo con el mundo exterior, el cosmos, con el cuerpo, con las teorías inventadas por el espíritu mismo y con las ideas. Concretamente, si nos situamos dentro de una perspectiva vital agustiniana, es decir, si nos colocamos en su vida, nos encontramos con que este primer movimiento negativo es la expresión de una lucha interna contra la supervaloración de la materia, contra las presiones de

1 Contra Academicos II, 5. 
la sensualidad, contra los mitos y las fábulas que pretendía imponer una cultura formalista, contra las diversas teorías en las que con tanta frecuencia se enajena el deseo angustioso de verdad y claridad.

No resulta difícil seguir este itinerario purificador de Agustín a través de las Confesiones en las que, sucesiva y dialécticamente, rechaza todo lo que no presenta $\mathfrak{u}$ ofrece una suficiente consistencia y certeza, ya que el alma "(...) certa sit non se esse aliquid eorum de quibus incerta est, idque solum esse se certa sit, quod solum esse se certa est" ${ }^{2}$. "Sólo debe tener certeza de su existencia, pues es lo único que sabe con toda certeza".

Esta fase negativa - cuando se halla asociada a la fase afirmativa, que podría llamarse preferentemente fase interrogativa - va a proporcionar una certeza, la gran aspiración de las almas en crisis y, para San Agustín, la verdadera condición o naturaleza de la felicidad: "Beatus crrare non potest" " "El hombre feliz no puede errar".

La certeza no podrá alcanzarse más que en la vida interior porque en ella solamente "Certe enim novit sibi dici, sibi scilicet quae est, et vivit, et intelligit" " "Tiene certeza que es a ella a quien se le preceptúa, es decir, a ella que existe, vive y comprende".

Pero si el camino de la interioridad da certeza de, no ofrece inmediatamente todos los grados de esa certeza, ni el terreno sobre el que se apoya este estado del espíritu.

A este primer momento de dialéctica negativa sucede un segundo momento en el que el alma continúa el sondeo de su propia naturaleza, porque "Nullo modo autem recte dicitur sciri aliqua res, dum eius ignoratur substantia" ${ }^{5}$. "No se puede con razón afirmar que se conoce una realidad cualquiera cuado se ignora su naturaleza". Ahora bien, la naturaleza del alma únicamente puede decirse determinada, precisada, cuando se la ha aprehendido intuitivamente como sujeto, como unidad, como centro de toda actividad.

Este descubrimiento de la naturaleza del alma como centro y dueña de los actos transforma enormemente el sentido de la interioridad que encontramos en la filosofía griega. Esta, preocupada por la eliminación de la subjetividad gnoseológica e incluso ética, acabará por reducir el

\footnotetext{
De Trinitate X, 10, 16 .

Contra Academicos IV 10.

De Trinitate $\mathrm{X}, 10,13$.

Ibid. $\mathrm{X}, 10,16$.
} 
espíritu a la objetividad de las ideas o de las formas, disolviendo, de esta manera, la interioridad propia de un sujeto auténtico.

Agustín deberá no solamente sobrepasar, superar, este plano de las ideas, lo que no hizo más que para unificarlas, sino que también, tan avido de la verdad como los filósofos griegos, reencontrará la objetividad sobre un plano diferente, dado que para él la subjetividad tiene otro sentido.

Donde mejor se aprehende la naturaleza de este plano óntico de la interioridad es en los comentarios acerca de al voluntad. La voluntad establece la unidad de toda la vida psíquica y, verdaderamente, se puede decir que ella es el alma: "Tertium vero solius animae est, quia voluntas est" " "La tercera, que es la voluntad, es exclusiva del alma". Ella es una fuente auténtica de iniciativas y de responsabilidad.

Solamente a través de este segundo momento de la dialéctica negativa se llega a alcanzar el centro de la vida interior, porque ella sola toca la verdadera fuente de toda vida humana. Si la conversión a la interioridad había sido compensada por una certeza, la conversión a una unidad superior de esta vida interior, la conversión a la voluntad, ilumina, esclarece e intensifica más aún la naturaleza de esta certeza: “(...) non enim quidquam tam firme atque intime sentio, quam me habere voluntatem (...)" " " Nada hay, en efecto, que sienta yo tan firme e íntimamente como que tengo voluntad...". Si el camino de la verdad era el de la interioridad, ahora únicamente es cuando ha sido alcanzado en su naturaleza auténtica. No se trata solamente de un control de la vida mediante el retorno a la interioridad, por oposición a la contigencia de los objetos exteriores, sino de una conversión a la voluntad, porque "(...) nihil tam in nostra potestate, quam ipsa voluntas est" ${ }^{8}$. "Nada está tanto en nuestro poder como nuestra misma voluntad".

Esta experiencia de la interioridad, por la que el hombre puede considerarse verdaderamente como una persona, trae consigo una doble consecuencia, casi paradójica. Esta experiencia, irreductible a cualquiera determinación, abre ante ella un horizonte infinito. Al sentirse irrealizada, puesto que le resulta imposible permanecer, sea cual fuere el lugar donde se encuentre, vive la angustia de sentirse imperfecta. All reencontrarse con la unidad, frente a la división a la que la tiene constreñida

Ibidem XI, 2, 5.

7 De Libero Arbitrio III, 1, 3.

8 Ibid. III, 3, 7. 
el mundo exterior o a la dispersión de los objetos de su propia conciencia, el espíritu no se siente, sin embargo, menos dividido, pues "(...) imperat, inquam, ut vellit, qui non imperat, nisi vellet, et non facit quod imperat" 9 . "Manda, digo, que quiera -y no mandara si no quisiera-, $y$, no obstante, no hace lo que manda".

No se trata, pues, para San Agustín de imponer una disciplina a la voluntad, eliminando la multiplicidad y las aporías de sus quereres y opuestos. Como no existe nada antes ni después de ella, el único movimiento dialéctico natural y espontáneo será la fidelidad a su horizonte inagotable, infinito.

Una vez estudiado este aspecto vamos a penetrar ahora en la fase esencial afirmativa.

\section{II}

Situados en el centro de la actividad de la voluntad, hemos superado ya las cargas negativas de los planos que no le pertenecen completamente, de la misma manera que nosotros renunciamos a imponerle cualquiera determinación que le resultaría extraña o la disminuiría. Ahora vamos a orientarnos por las exigencias de su propia naturaleza, de una amplitud infinita, la única realidad a la que deberemos ser fieles.

El esquema de esta fase afirmativa de la dialéctica y el paso a esta misma fase no nos va a resultar fácil por las dudas que nos va a hacer sufrir, al menos en lo que se refiere a las dificultades en orden al lenguajc que hemos de emplear. La causa va a ser la larga tradición ética conforme a la cual ha sido educado Agustín y que precisamente es de origen griego y romano. Con gran dificultad van a poder ser trasvasados aquí los ingredientes cristianos; puesto que rebasan los límites de un antropocentrismo extremo.

Elegiremos un concepto de inspiración estoica, que San Agustín atribuye a Terencio, porque, a través de los comentarios que hace de él, nos manifiesta sus propias preocupaciones: "Quoniam non potest id fieri quod vis, id vellis quod possis" ${ }^{10}$. "Porque no puedes hacer lo que quieres, quiere lo que puedes".

9. Confes. VIII, 9, 21.

10 In Andria, act. 2, scen. 1. 
San Agustín alude a esta máxima un gran número de veces, por ejemplo en De Beata Vita (IV, 25), De Trinitate (XIII, 7, 10) y De Civitate Dei (XIV, 25).

Existe una cierta evolución en el pensamiento de Agustín con relación a la manera de alcanzar la felicidad. $Y$ tal es la razón por la que tanto en el texto citado de De Beata Vita como en su contexto dicha sentencia es aceptada gustosamente por el Santo : "Etenim et illa eiusdem comici sententia, non minus vera est" ${ }^{11}$. "Pues no es menos verdadera la sentencia del mismo cómico...".

Aquí se ve que el Santo cultiva aún un ideal de vida interior en la que el dominio sobre la exterioridad resulta la nota más sobresaliente, y la propia interpretación de la voluntad se halla en función de esta capacidad de control de las aspiraciones: "¿Quomodo erit miser, cui nihil accidit praeter voluntatem?" ${ }^{12}$. "¿Cómo puede ser infeliz cuando nada le sucede contrario a su voluntad?".

Aunque la trascendencia sea ya el patrón de la verdad en De Beata Vita, es cierto, sin embargo, que San Agustín está aún muy marcado por el ideal de equilibrio, de moderación y mesura de la moral antigua. La felicidad será definida con relación a la parte más excelente del hombre, como se puede ver en Contra Academicos (II, 5), y que suscita luego un esclarecimiento en Retractiones (I, I, 2).

Pero diferente es el espíritu que preside el comentario a la misma máxima en $D e$ Trinitate y De Civitate Dei. Ahora Agustín considera como miserable la reducción de las aspiraciones de la voluntad a aquello que resulta sólo posible de realizar, a fin de alcanzar una felicidad posible: "Ideo igitur vult quod potest, quoniam quod vult non potest" ${ }^{13}$. "Quiere lo que puede porque no puede lo que quiere". Y añade a continuación: "¿Commode hoc dictum esse, quis negat? Sed consilium est datum misero, ne esset miserior. Beato autem, quales se esse omnes volunt, non recte nec vere dicitur: "non potest fieri quod vis". "Senten(ia asaz cómoda, ¿quién lo niega? Pero es consejo dado al indigente para que no sea más desgraciado. Al feliz, y todos queremos serlo, no sc le puede decir con razón y verdad: "lo que quieres es imposible".

Soportar las contrariedades inevitables o limitar las aspiraciones de

11 De eata Vita IV, 25.

12 Ibid.

13 De Trinitate XIII, 7, 10. 
la voluntad misma sería crear un ideal de felicidad reducido a las aspiraciones de un paciente miserable ${ }^{14}$.

El camino de la felicidad no puede hallarse, por tanto, en algo externo a la propia voluntad, ni siquiera en el dominio ejercido por ella, sino en la adecuación entre el querer y el poder, que no podrá realizarse más que teniendo en cuenta las infinitas aspiraciones de la voluntad, a las que debe corresponder un poder infinito. El ideal del poder se halla siempre presente, con una presencia total del espíritu a sí mismo, con una total plenitud, pero ahora se realiza de un modo infinito.

En la intimidad de la voluntad humana, Agustín siente que dentro de sí mismo se da realmente una división entre el querer y el poder, puesto que el hombre no puede lo que quiere. Esa adecuación o reajuste se va a realizar mediante la explicación del deseo profundo de la voluntad que equivale a sondear la verdad de la misma voluntad. Esta sólo se podrá alcanzar por un único camino posible, el de la interioridad, que es la misma voluntad. La voluntad recta conducirá al hombre hasta la felicidad, ya que en él el ser y el deber no se identifican aún y porque se distingue de los seres inferiores justamente porque no sólo vive sino porque se pregunta también cómo debe vivir : "(...) nam credo te memon ria tenere quam dixerimus esse bonam voluntatem : opinor enim, ea dicta est qua recte atque honeste vivere appetimus" ${ }^{15}$. "Creo recordarás cuál dijimos que era la buena voluntad; me parece dijimos que era aquella en cuya virtud deseamos vivir justa y honestamente".

Esto quiere decir que Agustín debe también buscar la verdad de su propia voluntad, mas, como su subjetividad no coincide con la de los filósofos griegos, esa objetividad se determina de manera diferente. Puesto que la voluntad no puede enajenarse en cualquier cosa que sea exterior a ella misma, el propio esquema griego de las ideas alcanzaría a la irreductible unidad y autonomía de la vida humana.

Una interminable dialéctica que acompañase a toda la gama de aspiraciones de la voluntad sería una ilusión o quimera de felicidad tan grave como su represión. Si la verdad no reside en la finitud ni en la determinación, aún menos residirá en un movimiento indefinido. Por consiguiente, hay que concluir que sólo puede encontrarse en el infinito.

Agustín ve esta angustia de querer ser y de deber abandonarse para

14 De Civitate Dei XIV, 25.

15 De Libero Arbitrio I, 13, 29. 
ser verdaderamente. Pero este abandono únicamente puede realizarse en relación a algo que será superior y nunca inferior a sí mismo. Mas he aquí que no existe nada superior a la interioridad de mi propia persona más que la interioridad de la persona infinita.

La voluntad no puede realizar la adecuación de su querer y de su poder mediante una dialéctica de ideas sino mediante un auténtico diálogo entre dos personas. Así como la unidad de la persona humana establece la unidad de toda la vida psíquica, de la misma manera la auténtica sabiduría no pertenece a un mundo de ideas, sino a la unidad de la persona, a la auténtica Sabiduría. Pues el Logos no es una idea, sino una Persona.

Lo que fundamenta la verdad de nuestra propia voluntad es la misma voluntad divina o, mejor dicho, la misma Persona del Verbo con la que dialogamos dentro de lo más íntimo de nosotros mismos: "(...) Deus meus, ne tu sileas a me. Tu loquere in corde meo veraciter" ${ }^{16}$. "Dios mío, que no calles tú para mí. Háblame tú verazmente en mi interior". El hombre no es, pues, su propia felicidad, sino Dios: "Cum enim te, Deum meum, quaero, vitam beatam quaero" 17. "Porque, cuando te busco a ti, Dios mío, la vida bienaventuarada busco". Este reencuentro de la persona divina con la humana, esencial en la felicidad, merced a la cual el hombre puede lo que quiere y quiere lo que puede, se 1ealiza, pues, en la misma intimidad del alma. Más que el resultado exclusivo de una dialéctica afirmativa en la que se explica la riqueza de una inagotable vida interior, es la presencia del propio Verbo lo que ha venido al encuentro del hombre.

La dialéctica agustiniana es, por tanto, un auténtico diálogo entre personas que supone una iniciativa de la trascendencia para ponerse al alcance del espíritu finito que se va a abismar en ella.

\section{P. Joaquín Cerqueira Gonçalves}

16 Confes. XII, 16, 23.

17 Ibidem X, 20, 29. 